\title{
A pandemic that's not bird flu? Pigs might fly
}

Sanjaya N Senanayake

$\mathrm{T}$ he world is potentially facing the first influenza pandemic of the 21 st century. This in itself is not a revelation, as influenza pandemics are cyclical phenomena; however, many would be surprised that we are dealing with "swine flu" instead of "bird flu".

\section{The story so far}

On 17 April 2009, the Centers for Disease Control and Prevention (CDC) in the United States revealed that a new strain of influenza virus had infected a 9-year-old girl and a 10-year-old boy living in adjacent counties in California. It was an $\mathrm{HlNl}$ virus closely related to swine influenza but with a genetic composition not identified to date in swine influenza isolates. Despite this, the children had relatively mild illnesses and made a full recovery. ${ }^{1}$ By 23 April, the CDC had announced five more cases of swine influenza $\mathrm{A}(\mathrm{H} 1 \mathrm{~N} 1)$ in the US, which included two small clusters (two 16-year-old boys from the same school in San Antonio, Texas, and a father and daughter from California). At the same time, the Public Health Agency of Canada revealed that Mexican authorities were seeking their aid in determining the cause of clusters of severe respiratory illness during April. ${ }^{2}$ By 25 April, Canada had confirmed that 18 cases of respiratory illness in Mexico were due to swine influenza $\mathrm{A}(\mathrm{H} 1 \mathrm{~N} 1)$, with 12 of these being genetically identical to the Californian virus. ${ }^{3}$

In the days since, more information has emerged about the Mexican outbreak, while more cases outside Mexico have also appeared. The situation in Mexico is widespread, involving Mexico City as well as many of the country's 32 states, including some bordering the US. It appears that the outbreak in the Federal District of Mexico (Mexico City) may have started as early as 18 March. ${ }^{3}$ To date, Mexican authorities have reported around 2000 cases of respiratory illness since 13 April, with almost 150 deaths, mainly affecting healthy young adults. ${ }^{4}$ These figures presumably underestimate the true burden of infection in Mexico as they only include hospitalised patients, ${ }^{3}$ however, at this time, all these hospital cases cannot be attributed to swine influenza with certainty on clinical grounds alone. The Mexican authorities have responded with various measures, including invoking emergency quarantine powers, shutting schools until 6 May, and handing out surgical masks to passengers using public transport. ${ }^{3,5}$

With regard to cases outside Mexico and the US, there are a number of countries with confirmed (Canada, Spain, United Kingdom, Israel, New Zealand, Costa Rica, Germany, Austria) and suspected (Australia, Brazil) cases. In Australia, there are 91 possible cases under investigation. ${ }^{6-9}$ In the US, there are now 91 laboratory-confirmed cases of swine influenza in 10 states, with one death attributed to swine influenza. ${ }^{10}$

\section{Swine influenza in humans}

Swine influenza is not a new phenomenon. The disease was first noticed in pigs during the influenza pandemic of $1918 .{ }^{11}$ Although very uncommon, human infection with swine strains has also been

eMJA Rapid Online Publication 1 May 2009

A further, updated article by the same author can be found at http://www.mja.com.au/public/issues/191_03_030809/sen10696_fm.html

\section{ABSTRACT}

- With the recent outbreak of swine influenza, the world may be facing this century's first influenza pandemic.

- In Mexico, around 2000 patients have been hospitalised with respiratory illness and almost 150 people have died. Several other countries have reported smaller numbers of suspected and confirmed cases of swine influenza.

- This 2009 influenza A virus is a strain of the H1N1 subtype, and appears to be a human-avian reassortment swine virus influenza.

- It is likely that sustained human-to-human transmission of swine influenza has occurred, at least in Mexico.

- Despite there being so many hospitalised patients in Mexico, cases outside Mexico have demonstrated a mild influenza-like illness, with only one fatality to date.

- In contrast to the 1918 influenza pandemic, we now have a more robust public health system, with widespread global networks; vaccines can be developed rapidly; and there are antiviral medications to which the swine influenza $A(H 1 N 1)$ virus is sensitive.

- Many resources have been invested in pandemic preparedness programs in the health care and public health systems in Australia over the past few years.

MJA 2009; 191: 38-40

well documented. One review identified 50 human cases in six countries from 1958 to 2005, with 13 cases occurring in military personnel and 37 in civilians. Probable limited human-to-human transmission was identified in two clusters of civilians. The median age of the civilian patients was 24.5 years. There was a high casefatality rate among civilians (17\%), all from pneumonia. The 13 military cases, including one death, occurred in Fort Dix, New Jersey, in $1976 .^{12}$

The influenza A virus responsible for the current outbreak, referred to as swine influenza, is a strain of the HlNl subtype, which has accounted for $90 \%$ of the historical civilian swine influenza cases previously described. Similar to five of the historical cases, the 2009 strain is a human-avian reassortment swine virus containing gene segments from North American swine, North American avian, North American human, and Eurasian swine influenza. ${ }^{12,13}$ This reassortment is no accident, as pigs contain receptors for both human and avian influenza strains. This means that pigs have the ability to serve as "mixing pots" for human and avian strains, potentially resulting in a novel virus to which humans have no immunity. ${ }^{11}$ Yet despite the 2009 strain being popularly labelled as "swine flu" by the global media, there is one glaring deficiency that is yet to be addressed, namely the lack of any epidemiological links to pigs. In their review of 50 human cases of swine influenza, Myers and colleagues were able to identify 22 that had a history of swine exposure. ${ }^{12}$ So far in 2009, despite seeing many hundreds more cases of "swine flu", there has been no documented exposure to pigs. To be fair, it is still too early in the outbreak investigation to make conclusions about its 


\section{CLINICAL UPDATE}

epidemiology — subsequent findings may identify exposure to pigs in some cases, especially in Mexico. But it is still likely that sustained human-to-human transmission of swine influenza has occurred, at least in Mexico - a feat that avian influenza A(H5N1) has been unable to consistently achieve in 5 years, except perhaps in a few isolated cases. ${ }^{14,15}$

\section{Pandemic potential and puzzling paradoxes}

Molecular and epidemiological studies will be needed in Mexico to determine the proportion of all reported cases of respiratory illness that is due to swine influenza. If swine influenza is the main culprit, then the virus appears to have pandemic potential. In addition to being capable of human-to-human transmission, the 2009 swine influenza virus appears to mainly affect healthy young adults aged $25-44$ years, including health care workers. ${ }^{2}$ This was a feature of the 1918 influenza pandemic that killed at least 40 million people. The case-fatality rate so far in Mexico is also very high, at around 6\%; although we must remember that this refers to $6 \%$ of hospitalised patients. There are presumably a number of mild or subclinical cases of swine influenza that have not as yet been identified. Confirmation of this would certainly lower the case-fatality rate; however, the case-fatality rate of young adults during the 1918 pandemic ranged from only 1\% to 3\%, but was still devastating due to the sheer numbers of people involved. Furthermore, the 1918 influenza pandemic came in three waves in a 1 -year period, the first of which was relatively mild. ${ }^{16}$

Despite its pandemic potential, there are also some puzzling paradoxes at this early stage of the outbreak that generate some optimism. The Mexican situation of 2000 suspected cases in hospitalised patients over a short period gives the initial impression of an infection with a fairly high attack rate and high rates of severe illness. Yet examination of the cases outside Mexico demonstrates a mild influenza-like illness, with only one fatality to date. Similarly, no large clusters of symptomatic or severe infection seem to have arisen from the cases outside Mexico, particularly from the early US cases. This may simply reflect that it is too early in the outbreak outside Mexico to see such patterns, which may eventually emerge. Nevertheless, it is an intriguing observation, and it also raises the question of whether there is more than one infection occurring in Mexico.

We also have a number of advantages now over the situation in 1918. One such advantage is the presence of a more robust public health system, with widespread global networks and the ability to communicate rapidly. Vaccines can now be developed within 3 months of an outbreak, although patients affected early will miss out. Antiviral medications exist to which the swine influenza $\mathrm{A}(\mathrm{H} 1 \mathrm{~N} 1)$ virus is sensitive, such as oseltamivir and zanamivir, ${ }^{6}$ although it is worth remembering that "standard" seasonal H1Nl influenza virus is becoming highly resistant to oseltamivir. ${ }^{17}$ There is therefore no guarantee of ongoing sensitivity of the swine influenza $\mathrm{A}(\mathrm{H} 1 \mathrm{~N} 1)$ virus to these agents. It is also important not to discount the role of antibacterial antibiotics during an influenza pandemic. Secondary bacterial pneumonia can fatally complicate primary influenza infection, so the place of antibiotics, which were not available in 1918, cannot be underestimated. In fact, there are hypotheses postulating that secondary bacterial pneumonias, rather than the influenza infection itself, were mainly responsible for the severity of the 1918 influenza pandemic. ${ }^{18}$ There is also the possibility that certain age groups may have an attenuated illness with swine influenza due to their immune systems being exposed to various $\mathrm{Hl}$ strains of influenza A over the years - but only time will tell if this is so.

\section{Australia's response}

Although developed with avian influenza particularly in mind, many resources have been invested in pandemic preparedness programs in the health care and public health systems in Australia over the past few years. ${ }^{19}$ This should hopefully provide some advantage in tackling the issue of swine influenza in Australia.

With regard to specific directives regarding swine influenza, on 27 April, the Australian Government introduced stricter border control measures for travellers returning from the Americas. For clinicians, case definitions have been developed to help identify suspected cases of swine influenza. From what little clinical data are available, swine influenza appears to initially cause a standard influenza-like illness, although vomiting and diarrhoea may be a more prominent feature than in "standard" influenza. ${ }^{2}$ The current definition of a suspected case is: ${ }^{20}$

a person with acute febrile respiratory illness with onset on or after 15 April 2009

* within 7 days of travel to Mexico, USA or Canada

or

* within 7 days of close contact with a person who is a confirmed or influenza A positive suspect case of swine influenza A (H1Nl) virus infection

An acute febrile repiratory illness is defined as a measured temperature of $38^{\circ} \mathrm{C}$ or greater OR a good history of fever, AND recent onset of one of the following symptoms: rhinorrhoea, nasal congestion, sore throat or cough.

An advisory has also been issued by the Chief Medical Officer instructing clinicians how to deal with a suspected case of swine influenza. $^{21}$

\section{Conclusion}

The sudden emergence of swine influenza in Mexico and other pockets around the world has generated extraordinary concern at all levels. The World Health Organization has now raised the level of influenza pandemic alert to Level 5 (out of 6 phases), defined as "sustained community level outbreaks in two or more countries in one WHO region". ${ }^{22,23}$ It is unclear at this stage how extensive and severe this outbreak will be, but if sustained local transmission is established in Australia, particularly during our normal influenza season, our resources and resourcefulness will be tested.

The information given here is current at the time of writing. It will undoubtedly change as further cases are identified, along with increased understanding of the epidemiology, clinical and molecular aspects of the infection.

\section{Competing interests}

None identified.

\section{Author details}

Sanjaya N Senanayake, MB BS, MAppEpid, FRACP, Infectious Diseases Specialist Department of Microbiology, Canberra Hospital, Canberra, ACT.

Correspondence: sanjaya.senanayake@act.gov.au 


\section{CLINICAL UPDATE}

\section{References}

1 Centers for Disease Control and Prevention. Swine influenza A (H1N1) infection in two children - Southern California, March-April 2009. MMWR Morb Mortal Wkly Rep 2009; 58: 400-402.

2 International Society for Infectious Diseases. ProMED-mail Archive Number 20090424.1541. PRO/AH/EDR> Influenza A (H1N1) virus, swine, human - USA (02): (CA, TX). 24 Apr 2009. http://www.promedmail.org/pls/otn/f?p= 2400:\%201001:\%201432717334138957::.:F2400_P1001_BACK_PAGE,F2400_ P1001_ARCHIVE_NUMBER,F2400_P1001_USE_ARCHIVE:\%201001, 20090424.1541,Y (accessed Apr 2009).

3 International Society for Infectious Diseases. ProMED-mail Archive Number 20090425.1552. PRO/AH/EDR> Influenza A (H1N1) virus, swine, human - N America. 25 Apr 2009. http://www.promedmail.org/pls/otn/f?p= 2400:\%201001:\%201432717334138957:.:.:F2400 P1001_BACK PAGE,F2400 P1001_ARCHIVE_NUMBER,F2400_P1001_USE_ARCHIVE:\%201001, 20090425.1552,Y (accessed Apr 2009).

4 BBC News. Mexico suspected flu toll soars. 27 Apr 2009. http://news.bbc.co. uk/2/hi/americas/8021656.stm (accessed Apr 2009).

5 International Society for Infectious Diseases. ProMED-mail Archive Numbe 20090426.1566. PRO/AH/EDR> Influenza A (H1N1) virus, swine, human - N America (03). 26 Apr 2009. http://www.promedmail.org/pls/otn/f?p= 2400:\%201001:\%201432717334138957 :...F2400 P1001_BACK PAGE,F2400 P1001_ARCHIVE_NUMBER,F2400_P1001_USE_ARCHIVE:\%201001, 20090426.1566,Y (accessed Apr 2009).

6 International Society for Infectious Diseases. ProMED-mail Archive Number 20090426.1577. PRO/AH/EDR> Influenza A (H1N1) virus, human: worldwide. 26 Apr 2009. http://www.promedmail.org/pls/otn/f?p= 2400:1001:1432717334138957::NO::F2400_P1001_BACK_PAGE,F2400_ P1001_PUB_MAIL_ID:1000,77215 (accessed Apr 2009).

7 WOAl.com. Swine flu outbreak forces closure of entire school district. $28 \mathrm{Apr}$ 2009. http://www.woai.com/content/health/story/Swine-flu-outbreak-forcesclosure-of-entire/GyWNCduLGEqo7SuvkrFQ9Q.cspx?rss=68 (accessed Apr 2009).

8 World Health Organization. Epidemic and Pandemic Alert and Response. Swine influenza - update 5. 29 Apr 2009. http://www.who.int/csr/don/2009_ 04_29/en/index.html (accessed Apr 2009).

9 Metherell M, Hudson P, Dart J. Sweeping new powers to detain, disinfect. Sydney Morning Herald 2009; 29 Apr. http://www.smh.com.au/national/ sweeping-new-powers-to-detain-disinfect-20090428-am34.html (accessed Apr 2009).
10 Centers for Disease Control and Prevention. Swine influenza (flu). http:// www.cdc.gov/swineflu/ (accessed 30 Apr 2009).

11 Vincent AL, Ma W, Lager KM, et al. Swine influenza viruses: a North American perspective. Adv Virus Res 2008; 72: 127-154.

12 Myers KP, Olsen CW, Gray GC. Cases of swine influenza in humans: a review of the literature. Clin Infect Dis 2007; 44: 1084-1088.

13 International Society for Infectious Diseases. ProMED-mail Archive Number 20090425.1557. PRO/AH/EDR> Influenza A (H1N1) virus, swine, human - N America (02). $25 \mathrm{Apr}$ 2009. http://www.promedmail.org/pls/otn/f?p= 2400:\%201001:\%201432717334138957::.:F2400_P1001_BACK_PAGE,F2400_ P1001_ARCHIVE_NUMBER,F2400_P1001_USE_ARCHIVE:1001, 20090425.1557, Y (accessed Apr 2009).

14 Wang H, Feng Z, Shu Y, et al. Probable limited person-to-person transmission of highly pathogenic avian influenza A (H5N1) virus in China. Lancet 2008; 371: 1427-1434.

15 Ungchusak K, Auewarakul P, Dowell SF, et al. Probable person-to-person transmission of avian influenza A (H5N1). N Engl J Med 2005; 352: 333-340.

16 Taubenberger JK, Morens DM. 1918 Influenza: the mother of all pandemics. Emerg Infect Dis 2006; 12: 15-22.

17 Moscona A. Global transmission of oseltamivir-resistant influenza. N Engl J Med 2009; 360: 953-956.

18 Brundage JF, Shanks GD. Deaths from bacterial pneumonia during 1918-19 influenza pandemic. Emerg Infect Dis 2008; 14: 1193-1199.

19 Preparing for an influenza pandemic [supplement]. Med J Aust 2006; 185 (10 Suppl): S25-S80.

20 NSW Health. Human swine influenza investigation. http://www.health. nsw.gov.au/publichealth/swine_flu.asp\#para_5 (accessed 1 May 2009).

21 Bishop J (Chief Medical Officer). Re: New swine influenza A strain in Mexico and the United States of America [letter to clinicians]. http:// www.health.nsw.gov.au/resources/publichealth/pdf/swine_flu_cmo_letter.pdf (accessed Apr 2009).

22 World Health Organization. Statement by WHO Director-General, Dr Margaret Chan. Swine influenza. 29 Apr 2009. http://www.who.int/mediacentre/ news/statements/2009/h1n1 20090429/en/ (accessed Apr 2009).

23 World Health Organization. Aide memoire: WHO pandemic phase descriptions and main actions by phase. http://www.who.int/csr/disease/influenza/ GIPA3AideMemoire.pdf (accessed Apr 2009).

(Received 28 Apr 2009, accepted 29 Apr 2009) 